4 Redaksi

Mata Banua

\begin{tabular}{l} 
PT Cahaya Media Utama, Banjarmasin \\
\hline
\end{tabular}

"Telah Terverifikasi Administrasi \&
oleh Dewan
No $552 /$ DP-Verfifikas//KN//2020

Terbit Pertama Kall :
10 Juli 2006

Pemimpin Umum :
HFachruddin Nor fransyah

Pemimpin Redaksi/Penanggungiawab:

Zanal Helmie

Penasehat Hukum :
Dr. H Fauzan Ramon,

Koordinator Peliputan:

Manager Produksi

"Aasmen Manager Pro
Rizky Yosfia Ruswita

Redaktur:
HA Fadillah, S

lin Silvia,
Nugraha

Biro-Biro/Perwakilan :

Rizal Fachrani (Jakarta), Herman Hidayat
(Tapin), Muhammad Yusuf (Hulu Sungai

Kabupaten Banjar), (Balangan)

Ebet Hadiani (Kotabaru) Risma (Tanah

Laut), Akhmad Alfiannor (Tanah Bumbu

Akhmat : iiza, Ro
Tauficaurarman

Produksi Iklan / IT Web :
Pahliawan Patria

Pahliawan Patria
Ibnu Zulkarnain

Pemimpin Perusahaan :

Sekretaris Perusahaan
Gusti Nur IIma Ariella

- Manager Iklan
Hj Noor Diana

Alamat Redaksi/Bisnis/Sirkulas :

e-Mail : redaksi_matabanua@yahoo.com

e-Mail Iklan : iklan.matabanua@yahoo.

Harga Langganan : Rp 75.000/bulan
dalam kota

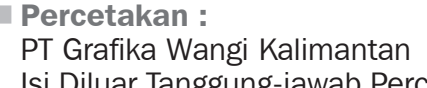

Tarif Iklan :

DISPLAY UMUM
Hitam Putih (BW)

Spot Colour (SC)
Full Colour (FC)

Hitam Putih (BW) : : Rp 13.000/mmk

$\begin{array}{ll}\text { Spot Colour (SC) } & : \text { Rp 15.000/mmk } \\ \text { Full Colour (FC) } & \text { : Rp 24.000/mmk }\end{array}$

$\begin{array}{ll}\text { DISPLAY HALAMAN } & \text { BELAKANG: } \\ \text { Hitam Putih (BW ) } & : \text { Rp 10.000/mmk } \\ \text { Spot Colour (SC) } & : \text { Rp 13.000/mmk } \\ \text { Full Colour (FC) } & : \text { Rp 22.000/mmk }\end{array}$

IKLAN KOLOM
IKLAN KELUARGA

Rp 8.000/ mmk

DUKA CITA
IKLAN BARIS

Rp $5.000 / \mathrm{mmk}$
$\mathrm{Rp} 5.000 / \mathrm{mmk}$

Catatan:
Harga belum terma
Pembayaran dimuka

\section{TELEPON PENTING}

\section{Polda Kalsel}

Poltabes Banjarmasin

Polsek Banjar Tengah

Polsek Banjar Barat

Polsek Banjar Timur

Polsek Banjar Selatan

Polsek Banjar Utara

KPPP Poltabes Banjarmasin

Polres Banjar

Polresta Banjarbaru

RSUD Ulin

RS Ansyari Saleh

RS Suaka Insan

RSIslam

RSDR Soeharsono

RS Siaga

RS Sari Mulia

RSUD Banjarbaru

PMK Hippindo

Rescue 911

3368571

3353003

441295

3252473

26124

3300463

4721110

2772266

3257472

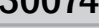

335222

3354896

3368422

3253111

3252570

4772380

7500911 9110911

REDAKSI menerima sumbangan tulisan opini, artikel maupun surat pembaca lainnya. Panjang tulisan opini/artikel
maksimal 3 (tiga) halaman kuarto, dike daksimal 3 (liga) halaman kuarto, dike dusaca isi tulisan opini dan artikel bukan mencerminkan sikap redaksi dan

merupakan tanggung jawab penulisnya. Redaksi berhak mengedit tulisan sepanja tidak mengubah esensi yang ada. Semua diri yang masih berlaku, dikirim Alamat Redaks/Bisnis/Sirkulasi:llPekapuran Rt 32 No 87 JI Lingkar Dalam Selatan

\title{
Isra Mikraj Momen Mewaspadai Diri
}

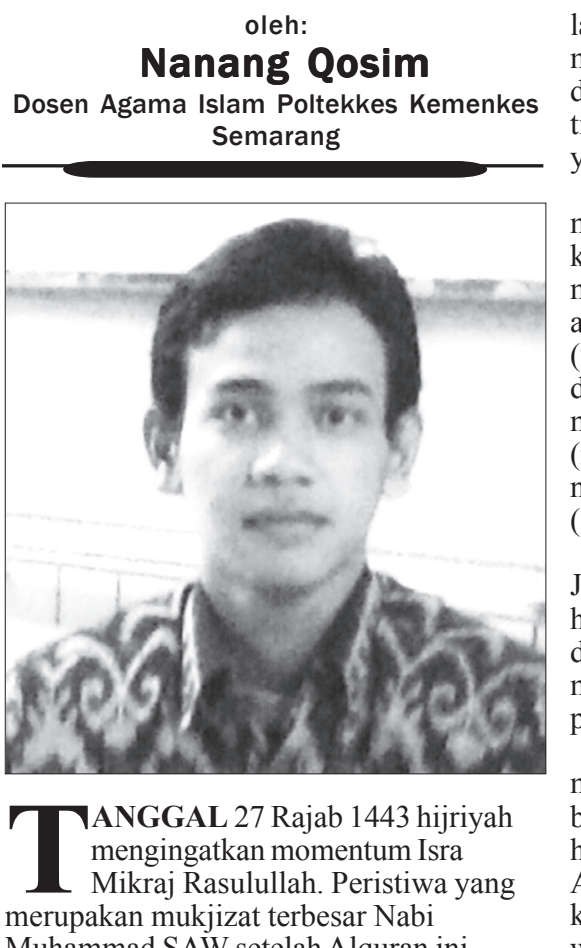

mengandung hikmah yang besar sekali.
Memperlihatkan tanda-tanda kebesaran-

Dalam Kitab al-Dardir yang khusus
menceriterakan peristiwa Isra Mikraj

menceriterakan peristiwa Isra Mikraj
merujuk sejumlah hadis, diperlihatkan
antara lain; ada orang yang memotong

lagi. Nabi bertanya siapa itu wahai I ibril
ttulah katanya contoh umatmu ketika

idup di dunia selalu berdusta.

dalah dusta. Ada orang yang memakan

aging yang lezat sekali. Ditanya kenap
emikian? Dikatakan bahwa ia selalu
nengghibah orang lain. Ada banyak ora

i neraka, itu umatmu juga wahai Rasul,
arena salah memanfaatkan waktu untuk
nunkarat, seperti banyak dilakukan ora

Kondisi demikian secara tida

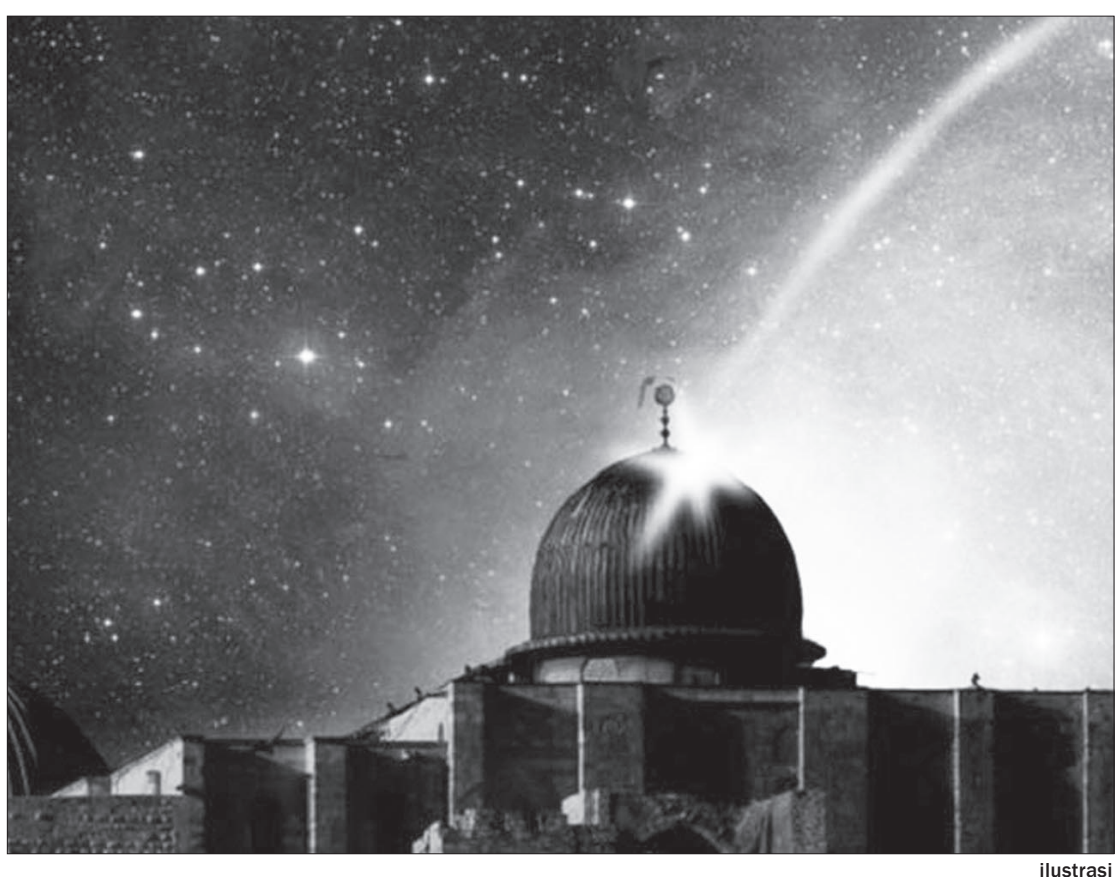

berpesan: Pagi hari kosongkan hati
tundukkan kepala, renungkan, kita in

berasal dari mana, sekarang berada di

Dengan demikian insya Allah katanya
seseorang akan bangkit kesadarannya
untuk bersifat tanang terpuji, beradad dalam

kebaikan-kebaikan dan menghindari
kemunkaran (munkarat).

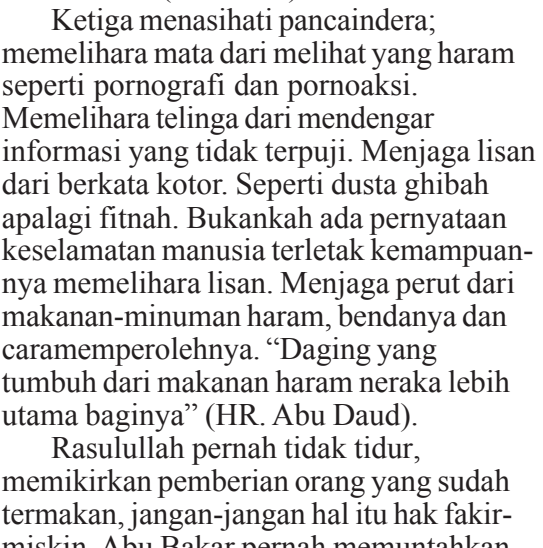

termakan, jangan-jangan hal itu hak fakir-
miskin. Abu Bakar pernah memuaknya dari peristiwa Isra Mikraj
salah satunya adalah ber-muhasabah

\section{Menyoal Fenomena Obat Kosong}

Zayanti Mandasarı

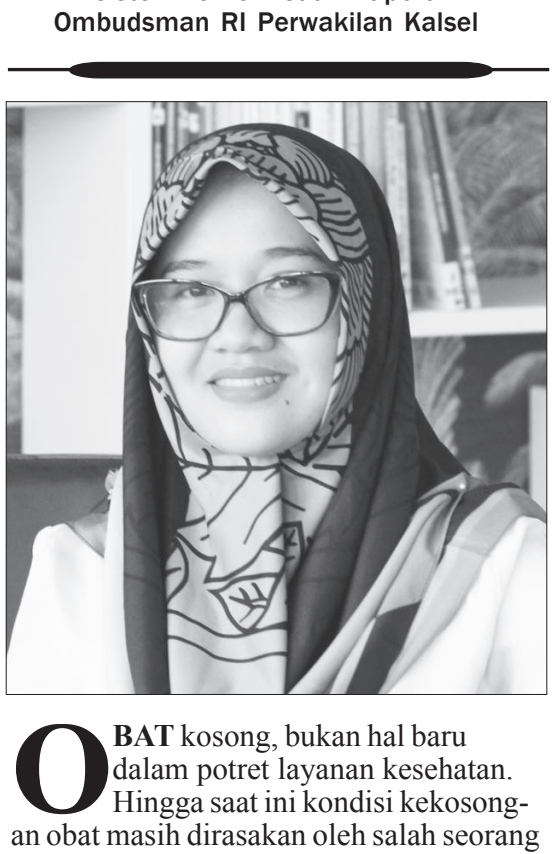

dirasakan oleh salah

plat merah di Kalimantan Selatas.
yang berobat menggunakan BPSS dokter ternyata tidak tersedia di apotek umah sakit. Sehingga pihak rumah sal
hanya memberikan bon obat, untuk
kemudian dapat mengambil obat dima

jika sudah tersedia, namum tak ada
kepastian kapan obat tersebut tere

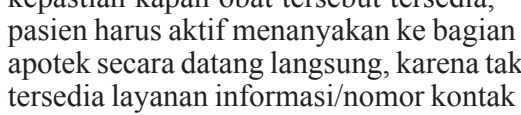

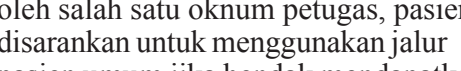

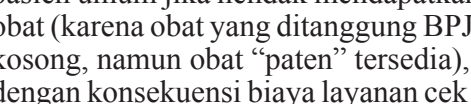

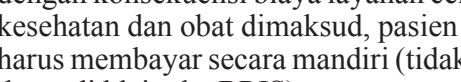

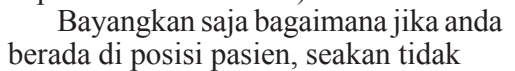

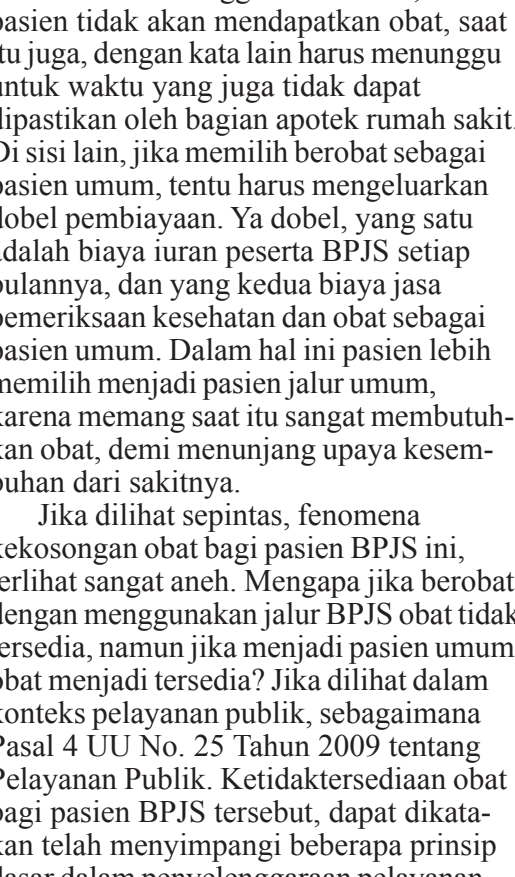

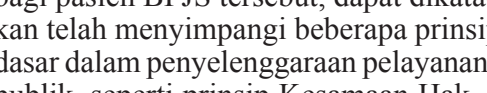

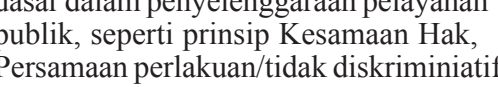

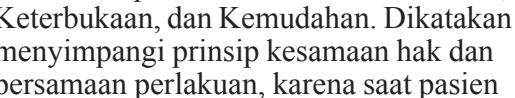

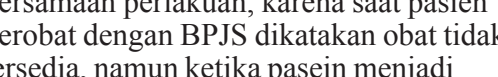

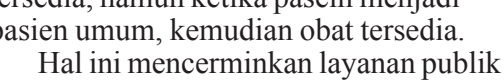

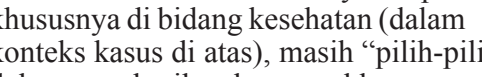

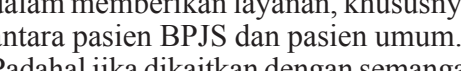

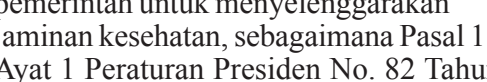

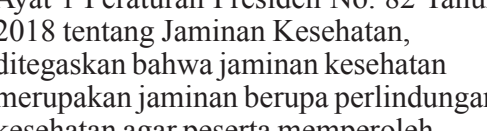

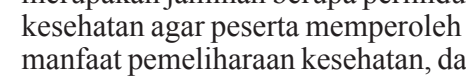

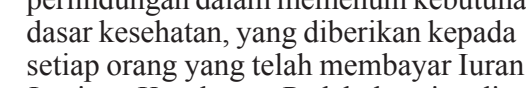

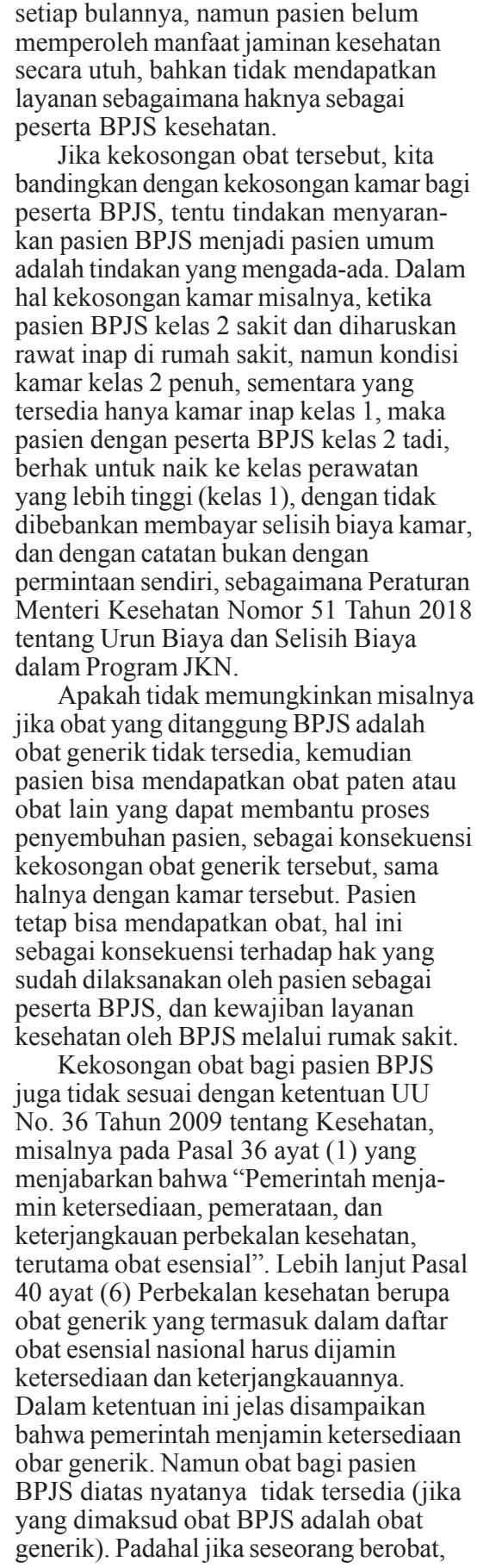

pemeriksaan dan pengobatan untuk
esembuhannya, saat itu juga. Sehingga

omena apotek memberikan bon oba inkron dengan tujuan layanan kesehat pelayanan kesehatan perseorangan
ditujukan untuk menyembuhkan penyakit Fenomena kosongnya obat bagi peserta
BPS tersebut tak hanya melulu soal fisik bat yang tidak tersedia, namun ada hal lain yang juga harus diperhatikan dan bat di apotek. Pada dasarnya keterbuka mejadi suatu keharusan sebagaimana UU ketersediaan obat juga akan berdampak khususnya pasien terhadap penyelenggara Dan tentunya menutup kran penyimpang-
an/penyelewengan obat untuk tujuan lain, leh oknum-oknum petugas yang tidak membawa citra buruk rumah sakit. Karen pada dasarnya pasien tidak mengetahu esep tersebut ke bagian apotek, dengan harapan dapat menerima obat.
Perlu diingat, bahwa kekosongan obat patum disyanan kesehatan, bukan hal yang
pathanakan, karena berdampak pada kesehatan seseorang. Harapannya baik di level pemerintah pusat maupun 列 hatan, yang harus dilaksanakan secar merata dan nondiskriminatif, sebagaiman enyelenggaraan kesehatan dapat terus makin baik, mudah, dan pasti. Sehingga 列
Sofi Nihayatul Kamilah

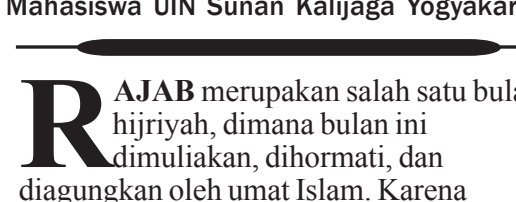

rdapat peristiwa penting

yang menjadikan umat muslim malaks
kan suatu perintah sebagai kewajiban.
Perstiwa tersebut ialah isra mi raj.

mendapatkan perintah perjalanan dar

Perjalanan semalaman itu berbuah hadiah

dilam berperilaku dalam kesechariannya.
Orang

terjaga dari kemungkaran.
Imam al-Ghazali menjelaskan bahw sholatnya maka akan sia-sia. Menging keadaan sholat sendiri ibarat sedang
berhadapan langsung dengan sang penc
alam semesta. Dengan ini, siapa yang

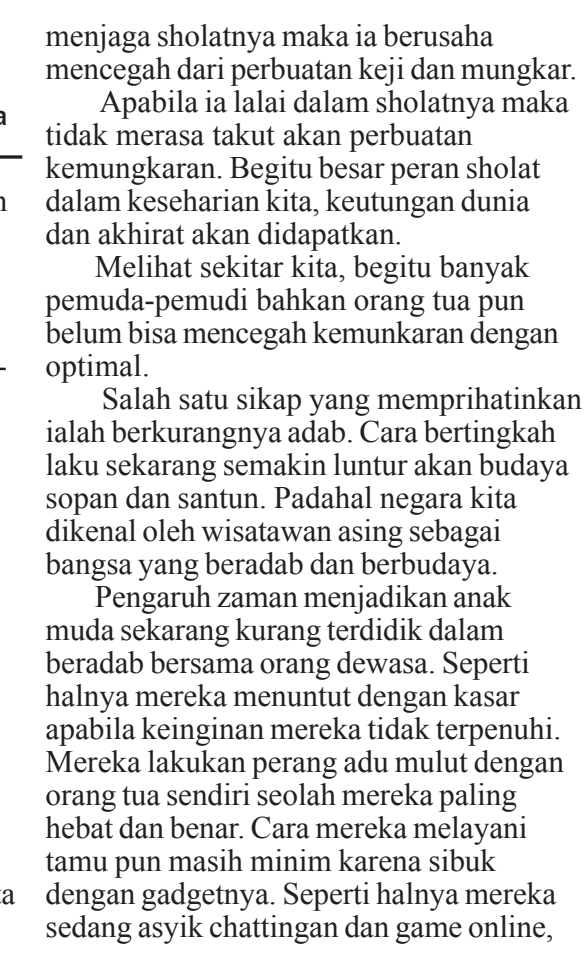

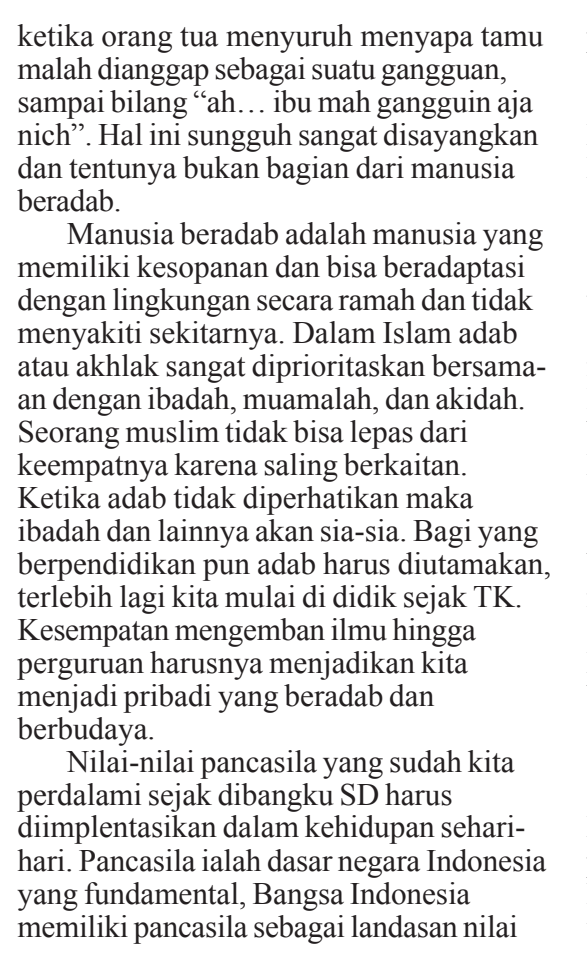

pengembangan ilmu dan akhlak atau etika ma dasar pedoman hidup bisa menjaciemanusiaan, nasionalisme, musyawarah, an taat pada tuhan-Nya. Percaya akan ipaksakan dan dibiasakan maka akan 位iliki semangat spiritual tinggi. an dengan manusia. Disit kitar agar senantiass toleransi dan bis 作- nilai ini jika dijalankan akan menjadi thatu kebanggaan tersendiri bagi bangsa u impian. Namun jika tikgi merup perhatikan maka akan menjadi suatu emahaman nilai-nilai yang baik yang 